A spectacular new genus of Staphylinini rove beetle from the tropical Andes and its phylogenetic assessment (Coleoptera

Staphylinidae)

Jenkins Shaw, Josh Jenkins; Zya, Dagmara Maria; Solodovnikov, Alexey

Published in:

Invertebrate Systematics

DOI:

10.1071/IS17020

Publication date:

2017

Document version

Peer reviewed version

Citation for published version (APA):

Jenkins Shaw, J. J., Zya, D. M., \& Solodovnikov, A. (2017). A spectacular new genus of Staphylinini rove beetle from the tropical Andes and its phylogenetic assessment (Coleoptera: Staphylinidae). Invertebrate Systematics, 31(6), 713-722. https://doi.org/10.1071/IS17020 


\section{A spectacular new genus of Staphylinini rove beetle from the tropical Andes and its phylogenetic assessment (Coleoptera : Staphylinidae)}

Josh Jenkins Shaw ${ }^{\mathrm{A}, \mathrm{B}}$, Dagmara Żyła ${ }^{\mathrm{A}}$ and Alexey Solodovnikov ${ }^{\mathrm{A}}$

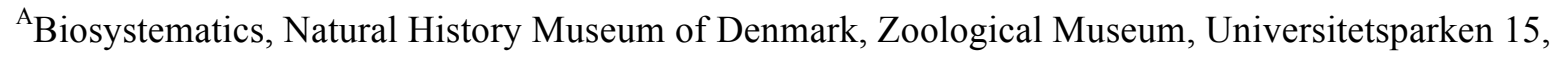
Copenhagen 2100, Denmark.

${ }^{\mathrm{B}}$ Corresponding author. Email: josh.shaw@snm.ku.dk

Devilleferus brunkei Jenkins Shaw \& Solodovnikov 2017, gen. et sp. nov., a distinctive new genus and species of Staphylinini rove beetle with an unusual set of morphological characters is described from the tropical Andes (Ecuador and possibly Colombia and Bolivia) in South America. To resolve systematic placement of the new genus within Staphylinini we assembled a dataset of 68 morphological characters scored for 34 taxa representing a broad sample of the respective rove beetle tribe, and performed Bayesian inference and maximum parsimony phylogenetic analyses. Both analytical methods unambiguously placed Devilleferus as sister to the subtribe Amblyopinina, and overall they corroborated recently established subtribal systematics for Staphylinini inferred mainly from molecular markers. Based on the shared synapomorphies, Devilleferus is assigned to the subtribe Amblyopinina. The internal relationships within Amblyopinina remain to be clarified in a broader study of that very poorly explored austral lineage.

\section{Introduction}

This paper is devoted to a remarkable large rove beetle that recently became known to us from photos as well as two specimens collected $\sim 150$ years apart and hitherto remained buried in museum collections. The tropical Andes of South America are considered a crucial biodiversity hotspot with the highest percentage of endemic plants and vertebrates in the world (Myers et al. 2000). This is almost certainly also the case for the insects there; however, the paucity of existing data prevents such conclusions being made. Knowledge of the insect diversity of the tropical Andes is fragmentary at best, especially for such hyper-diverse insect groups as rove beetles (Staphylinidae), which comprise $\sim 61500$ described species globally (Parker 2016). The discovery of a large and rare rove beetle from the tribe Staphylinini, whose conspicuous morphology did not allow its immediate placement among any subtribes and therefore triggered the analysis here, is a good illustration of that. Paleogeological events that formed the Andes have influenced the evolution and diversification of a multitude of organismal groups (e.g. Elias et al. 2009; De-Silva et al. 2016) and probably various rove beetle lineages, although neotropical rove beetles are too poorly known to study those processes. However, recent works on the tribe Staphylinini (Solodovnikov and Schomann 2009; Chatzimanolis et al. 2010; Brunke and Solodovnikov 2013; Brunke et al. 2016; Chani-Posse et al. 2017) have resolved its backbone phylogeny and therefore brought this group closer to such investigations; they also highlighted the phylogenetic diversity of Staphylinini lineages found in the neotropics. 
The tribe Staphylinini is a widely distributed monophyletic group of the subfamily Staphylininae comprising $\sim 5500$ species worldwide. As predators, members of the tribe are important components of terrestrial ecosystems, especially in biodiversity-rich microhabitats such as leaf litter, fungi, dung, carrion or rotting fruits. Several genera of Staphylinini in South America, which earlier formed the puzzling tribe 'Amblyopinini' (Seevers 1955), exhibit a unique mutualistic relationship with mammals (Ashe and Timm 1987; Solodovnikov and Jenkins Shaw 2016). Recent phylogenetic work showed that these mutualistic genera are nested within a diverse lineage of mostly free-living rove beetles in the south temperate regions (Solodovnikov and Schomann 2009; Chatzimanolis et al. 2010; Solodovnikov 2012; Brunke et al. 2016; Chani-Posse et al. 2017), which now altogether form the subtribe Amblyopinina. Although these mutualistic genera are well documented (Seevers 1944, 1955), the free-living members of the subtribe, which are much more speciose, lack modern taxonomic and phylogenetic treatment. Our newly discovered species shared some characters with free-living Amblyopinina, but it was too large and otherwise different to match any of the hitherto known members of that group. It should be noted that compared with other regions, the South American fauna of the free-living amblyopinines is known best because of the relatively modern treatment of the genera Cheilocolpus Solier, 1849 and Loncovilius Germain, 1903 for the southern part of South America (Coiffait and Sáiz 1966; Sáiz 1971), and the recent revision of the tropical genus Mimosticus Sharp, 1884 (Brunke and Solodovnikov 2014). Still, this undescribed species of a putative amblyopinine from the tropical Andes that we came across was truly remarkable, far from any of the known amblyopinine morphotypes. It was also quite remote from any large 'Staphylinini propria', represented in the neotropics by some Staphylinina, Philonthina and especially Xanthopygina, and different from either Valdiviodes Smetana, 1981 or Quediomacrus Sharp, 1884, the former genus considered as an isolated relictual branch of Staphylinini, and the latter a member of the quediine 'Quedionuchus-lineage' (Brunke and Solodovnikov 2013).

The unique, highly autapomorphic morphology of the rare target species left no doubts about its status as a new genus and species, Devilleferus brunkei Jenkins Shaw \& Solodovnikov 2017, gen. et sp. nov. within the tribe Staphylinini. But its sister-group relationships within Staphylinini, and thus its subtribal position, were not obvious from a preliminary morphological examination. Therefore, here we explore its placement within the tribe by means of phylogenetic analysis of morphological data using Bayesian inference and maximum parsimony. Molecular data for Amblyopinina are too incomplete to be used for phylogenetic purposes, while DNA-grade material for our new genus and some rare genera such as Quediomacrus are not available at all.

\section{Materials and methods}

\section{Microscopy and illustrations}

Beetles were studied as either dry mounted specimens or as disarticulated wet preparations in glycerin. Dissected genitalia and terminal segments of the abdomen were partially macerated in $\mathrm{KOH}$, washed with distilled water, placed in a plastic vial containing glycerin and pinned under the respective specimen. The 
distribution map was created using SimpleMappr (Shorthouse 2010). Measurements were taken using an ocular micrometer and are abbreviated as follows: HL, head length (from apex of clypeus to neck constriction); HW, head width (maximal, including eyes); PL, pronotal length (along medial line); PW, pronotal width (maximal); EL, elytral length (from humerus to most distal apical margin; best taken from lateral view of the elytron); EW, combined width of both elytra (maximal, with elytra closed along suture); forebody length was calculated as the sum: $\mathrm{HL}+\mathrm{PL}+\mathrm{EL}$; total length of the body was measured from the tip of mandibles to the tip of the abdomen. Type labels are repeated verbatim and each label is separated with a forward slash (/). Additional information is given in square brackets. To the holotype and paratype, we attached our standard red and yellow labels, respectively.

\section{Material and collections}

The two specimens of Devilleferus brunkei studied here and four further specimens, three of which were studied from photos, are deposited in the following institutions: CIUQ, Colección de Insectos de la Universidad del Quindío, Colombia; CMNH, Carnegie Museum of Natural History, USA (paratype); ICN, Instituto de Ciencias Naturales, Universidad Nacional de Colombia, Colombia; MSUC, Michigan State University, USA; RBINS, Royal Belgian Institute of Natural Sciences, Belgium (holotype).

\section{Taxa}

The taxon sample used in the present study was based on the matrix used in Brunke and Solodovnikov (2013). The sample was trimmed to include 34 taxa for our analysis. Preliminary examination of Devilleferus suggested that the subtribe Amblyopinina was most likely to contain a sister taxon for the genus and therefore we increased coverage of that subtribe in our phylogenetic analysis. The following Amblyopinina were added to the matrix: Quedius sidneensis Fauvel, 1877 (Australia), Quedius viridulus Erichson, 1840 (Bolivia), Sphingoquedius strandi Bernhauer, 1941 (New Zealand), Amblyopinus emarginatus Seevers, 1955 (Panama), Cheilocolpus impressifrons Solier, 1849 (Chile) and Loncovilius (Lienturius) leiocephalus Solier, 1849 (Chile).

\section{Characters}

Characters in the matrix of Brunke and Solodovnikov (2013) were chosen based on their utility in resolving relationships at the higher level within Staphylinini. The character choice was therefore appropriate for determining the most likely placement of the new genus within Staphylinini. The final matrix comprised 68 characters (Table 1) trimmed from the original 79 characters analysed in Brunke and Solodovnikov (2013). Eleven characters were removed because they became uninformative with the altered taxon sample or they only applied to taxa that were trimmed. Character 4 is a novel character from a new, hitherto unpublished data matrix targeting Staphylinini phylogeny under construction by Adam Brunke, which we use here with his permission. 


\section{Phylogenetic analysis}

The character matrix was constructed in Mesquite ver. 3.04 (Maddison and Maddison 2015). Unknown character states were coded with '?' and inapplicable states with '-'. The character matrix used in the present study can be downloaded as supplementary material to the present paper or from MorphoBank (http://morphobank.org/permalink/?P2624). Characters were treated as unordered and equally weighted. To test the phylogenetic placement of the new genus, we analysed our data matrix using Bayesian inference (BI) in MrBayes v. 3.2.6 (Ronquist et al. 2012) on XSEDE via the CIPRES Science Gateway (Miller et al. 2010). We used the Mkv model and priors were set to default. Analyses consisted of four chains and two runs of 15 million generations and were repeated twice. They were conducted with gamma distribution. Markov chain Monte Carlo convergence was visualised in Tracer v. 1.6 (Rambaut et al. 2014) as well as by the examination of PSRF (potential scale reduction factor) values and average standard deviation of split frequencies in the MrBayes output. Posterior probabilities over 0.8 are reported on their respective nodes. The BI consensus tree was visualised using FigTree v. 1.4.2 (Rambaut 2014).

In addition to BI, we also carried out maximum parsimony (MP) analysis. Our data matrix was computed in TNT (Goloboff and Catalano 2016) using the 'traditional search' option under the following parameters: memory set to 99999 trees, 1000 replicates, 100 trees saved per replicate, trees collapsed after search. Platyprosopus mexicanus Sharp, 1887 was set as the outgroup. Bremer support was calculated in TNT (Goloboff and Catalano 2016) using suboptimal trees up to 20 steps longer. Character states were mapped onto the MP strict consensus tree using WinClada v. 1.00.08 (Nixon 2002) under unambiguous optimisation.

\section{Results}

\section{Phylogenetic analysis}

The BI analysis converged well before 15 million generations and the final average standard deviation of split frequencies stabilised well below 0.01. Most PSRF values were 1.000 (maximum value 1.001). The consensus tree is shown in Fig. 1. When autapomorphic characters of Devilleferus were included in the BI analyses (meso- and metatibia with long bifurcated apical spur on the inner margin), there was no difference in topology or support. The MP analysis using traditional search resulted in 96 most parsimonious trees with 228 steps, consistency index $(\mathrm{CI})=0.35$ and retention index $(\mathrm{RI})=0.64$. The strict consensus tree with characters mapped and Bremer support (in red) is shown in Fig. 2.

Both BI and MP supported largely the same topology, at least with regards to the monophyly of major subtribes within Staphylinini (Figs 1,2). In both analyses, Devilleferus brunkei was resolved as sister to all sampled Amblyopinina. The latter subtribe including Devilleferus brunkei was monophyletic in all analyses with posterior probabilities (PP) $=0.94$ in the BI (Fig. 1) and Bremer support 2 in the MP (Fig. 2). Amblyopinina, excluding Devilleferus brunkei, was supported by $\mathrm{PP}=0.84$ in the $\mathrm{BI}$ and Bremer support 1 in the MP. The internal relationships of Amblyopinina were largely congruent between MP and BI; however, 
sister-group relationships of several taxa within that subtribe were unresolved. Given such topology, we should either erect a new subtribe for Devilleferus or include it in the subtribe Amblyopinina. We prefer the latter solution because Devilleferus shares some characters that are diagnostic for Amblyopinina.

The results of both BI (with very high support) and MP (with low support) placed Devilleferus brunkei as a lineage sister to the subtribe Amblyopinina (Figs 1,2). The MP analysis recovered two characters as unambiguous synapomorphies of Amblyopinina including Devilleferus: paramere strongly produced over apex of median lobe (66-1) and paramere attached to median lobe at base, closely appressed to median lobe along entire length (67-1). In addition, the MP analysis optimised the mesoscutellum without posterior scutellar ridge as a homoplastic synapomorphy (33-0), the other taxa with this character being Platyprosopus mexicanus and Arrowinus peckorum Solodovnikov \& Newton, 2005, representatives of the Staphylininae tribes Platyprosopini and Arrowinini, respectively.

\section{Taxonomy}

\section{Subtribe AMBLYOPININA Seevers}

Genus Devilleferus Jenkins Shaw \& Solodovnikov, gen. nov. http://zoobank.org/urn:1sid:zoobank.org:act:2432F335-6D22-4C32-AAC7-A4D25360E4CF

Type species: Devilleferus brunkei Jenkins Shaw \& Solodovnikov, sp. nov.

\section{Diagnosis}

Habitus as in Fig. 3. Within Staphylinini and Amblyopinina the new genus may be recognised based on the following combination of characters of the adult morphology: overall large size (26.5 to $27.0 \mathrm{~mm}$ from the tip of the mandibles to the tip of the abdomen); head with gular sutures converging medially; tomentose pubescence on antennomeres $\mathrm{V}-\mathrm{XI}$; pronotal hypomeron strongly inflexed and thus not visible in lateral view (homoplastic synapomorphy of Amblyopinina), with a large well-sclerotised post-coxal process; mesoscutellum with only anterior transverse carina (Fig. $4 A$ ); each elytron with the lateral area covered with dense golden setae (Fig. 3); protergal glands present, manifested as shallow impression (Fig. 4B); hind wings fully developed, veins MP4 and CuA separate, MP3 present (wing venation abbreviations according to Kukalová-Peck and Lawrence 1993) (Fig. 5A); meso- and metatibia with long bifurcated apical spur on the inner margin (Fig. $5 B$ ); apical tarsal segment with pair of empodial setae; aedeagus with paramere attached to median lobe at base (synapomorphy of Amblyopinina) and closely appressed along its length (synapomorphy of Amblyopinina), without peg setae (Fig. 5C-E). 


\section{Description}

Large rove beetle superficially resembling the genus Creophilus Leach, 1819 or Quediomacrus. Head capsule quadrate. Eyes a quarter of size of head (from antennal insertions to temples). Mandibles rather long and sharp, crossing each other when closed; apical third of each mandible somewhat angulate; dorsal mandibular ridge present, extending two-thirds along length of mandible, punctured along its length; each mandible with three teeth. Vertex of head with shallow impression between eyes. Neck distinct with scattered punctures; nuchal ridge present dorsally and laterally, ventrally extending just beyond postgenal ridge; dorsal basal ridge absent. Temples punctate and setiferous. Labrum bilobed with long black macrosetae forming a mat, some extending to around half the length of mandibles. Gular sutures converging medially, but continued as two separate entities posteriorly and anteriorly. Antennal insertions not concealed from above; antennomeres one to five elongate; six quadrate; seven to 11 elongate. Antennomeres one to four setiferous; five to 11 setiferous and with tomentose pubescence. Ligula entire, notched apically. Maxillary palpi four-segmented; apical segment fusiform, slightly longer than penultimate segment, without setae. Labial palpi three-segmented; apical segment fusiform, almost twice as long as penultimate segment, without setae.

Prothorax. Disc of pronotum glabrous, without dorsal series of punctures; micropunctures present throughout; weak microsculpture present on lateral areas of pronotal disc. Anterior angles of pronotum strongly produced beyond anterior margin of prosternum; superior marginal line well developed, not deflexed ventrally. Hypomeron strongly inflexed and therefore not visible in lateral view; large, wellsclerotised post-coxal process present. Notosternal sutures present. Basisternum transverse, distinctly longer than furcasternum, with transverse carina. Prosternal process of basisternum acutely pointed with apical point recurved and slightly directed anteriad.

Mesothorax. Mesoscutellum with only anterior transverse carina (Fig. 4A). Elytra slightly longer than wide, covered in dense cellular microsculpture and therefore matt, lateral area of each elytron with dense golden setae (Fig. 3); each elytron with humeral projection bearing spine-like setae; sub-basal ridge present; sinuate, laterally directed anteriad (Fig. 4A). Mesoventrite with dense setation; without transverse carina; mesosternal process produced, acutely angled at apex. Meso-metasternal suture (sensu Solodovnikov 2006) present.

Metathorax. Hind wings fully developed; veins MP4 and CuA separate; vein MP3 present (Fig. 5A).

Legs. Moderately long, covered in setae; tarsal formula 5-5-5. Both sexes with anterior tarsi expanded, tarsomeres I-IV with white adhesive setae ventrally. Dorsal surface of protibiae, profemora and procoxae covered in macrosetae. Meso- and metatibiae with long bifurcated apical spur on the inner margin (Fig. 5B). Claws large; apical tarsal segment with pair of empodial setae. 
Abdomen. Matt black; dorsoventrally flattened; parallel-sided, narrowed apicad from abdominal segment VII. Pair of protergal glands on tergite I manifested as shallow cuticular impressions (Fig. 4B). Tergite II with basal longitudinal carina entire, connecting anterior margin of tergite with transverse basal carina. Segments III-VI each with two pairs of elongate paratergites. Segment VII also with two pairs of paratergites, but anterior paratergite slightly shorter than posterior, with diagonal ridge. All tergites with anterior basal carina situated well anterior to spiracles, posterior basal carina absent. Sternites III and IV with transverse carina, rounded. Sternites VII, VIII and lateral tergal sclerites IX with long black macrosetae.

\section{Remarks}

We are aware of four specimens that were unfortunately unavailable for study; however, we received photos of three of them. Based on overall habitus similarity and characters that we could observe in the photos, the respective specimens were clearly assigned to Devilleferus. Although they look identical to D. brunkei (described below), the male genitalia must be studied before species identification can be made. Two of the mentioned specimens were collected from the tropical Andes in Colombia (Fig. 6) and their locality data are as follows: specimen $1\left({ }^{\Uparrow}\right)$, 'Colombia, Quindío, Calarcá, Vereda Planadas, Reserva la Sonadora $4^{\circ} 25^{\prime} 48.9^{\prime \prime} \mathrm{N}, 75^{\circ} 36^{\prime} 57.8^{\prime \prime} \mathrm{W}$, Manual $2991 \mathrm{~m}, 15$. ii.2013. Col. D. Hoyos y J.' (CIUQ); specimen 2 (sex unknown), 'Colombia, Cauca, Belalcazar, La Termal, 3208 m, 27.x.1980' (ICN). And two more specimens were collected from the tropical Andes in Bolivia (Fig. 6) with their locality data as follows: $2 \hat{\alpha}$, 'Bolivia: Dept. Cochabamba: El Limbo, 2000 m, March 1962, F. H. Walz.' (MSUC).

\section{Distribution and bionomics}

The new genus is only known based on two specimens from Ecuador (here examined), two specimens from Colombia and two specimens from Bolivia (see 'Remarks' above) (Fig. 6).

\section{Etymology}

Based on the green label attached to the holotype of D. brunkei, the specimen seems to have been collected by Émile Deville (also sometimes referred to as Émile De Ville), a French naturalist who collected various insect groups in South America in 1843. The generic name is derived from the combination of his surname and the Latin word 'ferus' meaning 'beast', due to the large and robust appearance of the species. The generic name is masculine.

Devilleferus brunkei Jenkins Shaw \& Solodovnikov, sp. nov.

http://zoobank.org/urn:1sid:zoobank.org:act:2EE039FC-0C3E-4C3A-8A13-BD533F14D01E 


\section{Material examined.}

Holotype. Ecuador: $\widehat{\delta}$ (card mounted with apical segment of abdomen and aedeagus in glycerin vial pinned under specimen), 'Ecuador 71 E. de Ville [green label] / Dèsiré [label presumably indicating that someone wished to keep this specimen] / Quedius? nov.gen? sp. nov. [handwritten label]' (RBINS).

Paratype. Ecuador: $P_{+}$(point mounted). 'Ecuador: Napo, Oyacachi, 3200 m, 28 January 1993, Giovanni Onore' (CMNH).

\section{Description}

Habitus as in Fig. 3. Measurements (in mm): large beetles, total body length 26.5-27.0. Male: HL 4.0, HW 4.0, PL 4.0, PW 5.0, EL 6.5, EW 6.0, total length 26.5. Female: HL 3.5, HW 4.0, PL 4.5, PW 5.0, EL 7.0, EW 6.0, total length 27.0.

In addition to characters given in the genus description, the new species is characterised by the following primary and secondary sexual characters.

\section{Male}

Apical margin of sternite VIII with incision. Sternite IX widest in the middle with apical area weakly emarginate; basal portion strongly asymmetrical. Aedeagus as in Fig. 5C-E. Paramere attached to median lobe at base and closely appressed along its length, slightly produced over apex of median lobe; without peg setae but with long setae situated before the apical point of paramere. Median lobe with broad sclerites protruding from internal sac over apical area.

\section{Female}

Head with pair of weak tubercules, one on each side of a shallow impression on vertex between eyes. Apical margin of sternite VIII without incision.

\section{Etymology}

The species name is patronymic. It is with pleasure that we dedicate it to our friend and colleague Adam Brunke, who found four specimens of Devilleferus in museum collections and brought our attention to the fact that it could be a member of the subtribe Amblyopinina.

\section{Discussion}

Overall, the results of our analyses were congruent with recent phylogenetic work on the tribe Staphylinini (see Solodovnikov and Schomann 2009; Chatzimanolis et al. 2010; Brunke and Solodovnikov 2013; Brunke et al. 2016; Chani-Posse et al. 2017). As the main goal of the analysis presented here was to assess the phylogenetic placement of a new genus within the tribe Staphylinini, we do not discuss phylogenetic results for Staphylinini in general. It should be noted, though, that in both our analyses the recently recognised subtribe Cyrtoquediina (Brunke et al. 2016) was resolved as sister to Amblyopinina, which is contrary to recent molecular (Brunke et al. 2016) and combined molecular and morphological (Chani-Posse et al. 2017) 
analyses that proposed the sister relationship of Afroquedius Solodovnikov, 2006 to a monophyletic Amblyopinina. This relationship was supported by both ML and BI (PP =1.0) in Brunke et al. (2016), but was unsupported in the analyses of Chani-Posse et al. (2017). In the morphology-only analysis of Brunke and Solodovnikov (2013), Amblyopinina was resolved as sister to the 'Quedius complex' including the Acylophorina. Cyrtoquediina, then part of the 'basal grade Staphylinini', was recovered as sister to Amblyopinina + Quediina + Acylophorina, similar to the results presented here, albeit our analysis included fewer taxa (Figs 1, 2). In their analyses, the genus Atanygnathus Jakobson, 1909 was nested within Amblyopinina; however, recent molecular results support the placement of Atanygnthus in its own subtribe, Tanygnathinina, which was sister to Amblyopinina (Brunke et al. 2016; Chani-Posse et al. 2017). These discrepancies among various analyses stress the difficulty of resolving early divergences within the Staphylinini with a high degree of precision.

The analysis of Brunke and Solodovnikov (2013), from which the matrix presented here was adapted, optimised two characters as synapomorphies of Amblyopinina: aedeagus with parameres projecting over the apex of the median lobe, and the sub-basal ridge present on each elytron horizontal but reduced. In contrast to the latter synapomorphy, Devilleferus has the sub-basal ridge on each elytron sinuate, directed anteriad. Brunke and Solodovnikov (2013) also recovered two homoplastic synapomorphies: mesoscutellum without posterior scutellar ridge and wing veins $\mathrm{CuA}$ and MP4 fused. Our results further emphasise the 'Quedius problem' highlighted by Solodovnikov (2006), but which is gradually being solved (Brunke and Solodovnikov 2013; Brunke et al. 2016). Several species currently incorrectly placed in Quedius ( $Q$. antipodum, Q. sidneensis and Q. viridulus) were placed in Amblyopinina by both analyses here, consistent with the earlier morphological and molecular phylogenies (Chatzimanolis et al. 2010; Brunke and Solodovnikov 2013; Brunke et al. 2016) that used Q. antipodum. That species shares all synapomorphies of Amblyopinina with $Q$. sidneensis and $Q$. viridulus. Many species described as Quedius (subtribe Quediina) from Australia, New Guinea, New Zealand, and South and Central America will be moved to their proper genera in Amblyopinina in due course (J. Jenkins Shaw and A. Solodovnikov, in prep.).

Given that Devilleferus has the synapomorphies of Amblyopinina, which were recovered in the analyses of Brunke and Solodovnikov (2013) and in our analyses here, we classify Devilleferus as a member of the subtribe Amblyopinina rather than erect its own new subtribe, even though the new genus is quite characteristic. In addition to the character states recovered as synapomorphies of Amblyopinina inclusive of Devilleferus in our analyses (paramere strongly produced over apex of median lobe and paramere attached to median lobe at base, closely appressed to median lobe along entire length), the new genus also has the pronotum with hypomeron strongly inflexed and aedeagus without peg setae. The former character (pronotum with hypomeron strongly inflexed) is highly homoplastic (Brunke et al. 2016), which probably contributed to the 'Quedius problem' (Solodovnikov 2006) and led an earlier worker to leave a question on the label about whether Devilleferus was a species of Quedius or a new genus presumably closely related to 
Quedius (see 'Material examined' above). With very few exceptions, the latter character (aedeagus without peg setae) is stable; a great majority of species of Quedius and Quediina have the paramere of the aedeagus with peg setae in various arrangements. On the contrary, the great majority of Amblyopinina do not have them or, in very few exceptional cases when they have, their peg setae are pale and sharp, in contrast with the dark and obtuse peg setae in Quediina, suggesting their independent origin in the respective groups. An interesting autapomorphy of Devilleferus brunkei is the birfucate spurs on both the meso- and meta-tibiae (Fig. 2B), which as far as we are aware do not occur in any other taxon of Staphylinidae, or potentially even Coleoptera. It is noteworthy that, despite some habitus similarity and several character states shared by Devilleferus with the neotropical genus Quediomacrus (gular sutures converging medially; tomentose pubescence on antennomeres $\mathrm{V}-\mathrm{XI}$; pronotal hypomeron strongly inflexed, with a large well-sclerotised post-coxal process; humeral angles of elytra with small projection and spine-like setae; hind wings with veins MP4 and CuA separate), these genera are not close phylogenetically. Consistent with Brunke and Solodovnikov (2013), Quediomacrus is closely related to the Australian genus Lonia Strand, 1943 in our analysis.

Biogeographically, Devilleferus presents an interesting taxon among Amblyopinina. Within South America, most free-living Amblyopinina are found in Chile and Argentina, for example, the species-rich genera Loncovilius and Cheilocolpus. Based on our study of extensive material, there is a notable decrease in Amblyopinina diversity in the northern countries of South America: Brazil, Peru, Colombia and Ecuador. Therefore, the apparent geographical isolation of Devilleferus in combination with its unusual morphology make it a target taxon for our planned molecular phylogeny of Amblyopinina. We hope that our description will encourage entomologists to collect DNA-grade material of this amazing species.

\section{Acknowledgements}

We are especially grateful to Adam Brunke (Ottawa) who found four of the specimens of Devilleferus brunkei and always shared with us his enthusiasm and insights on the phylogeny and systematics of Staphylinini. We thank the curators and collections managers of the institutions listed in the 'Materials and methods' section for the loan of specimens. Thanks to Diana Méndez and Margarita López for providing locality data and photos of the two specimens from Colombia which were unavailable for study. TNT was made freely available by the Willi Hennig Society (cladistics.org) and the CIPRES Scientific Gateway provided access to computational resources. A. Newton, S. Chatzimanolis and one anonymous reviewer provided comments and suggestions that significantly improved this manuscript. This project has received funding from the European Union's Horizon 2020 research and innovation program under the Marie Skłodowska-Curie grant agreement no. 642241 and was partially supported by the Villum Foundation (block postdoctoral scholarship for DŻ).

\section{References}

Ashe, J. S., and Timm, R. M. (1987). Probable mutualistic association between staphylinid beetles (Amblyopinus) and their rodent hosts. Journal of Tropical Ecology 3, 177-181. doi:10.1017/S0266467400001978 
Brunke, A. J., and Solodovnikov, A. (2013). Alesiella gen.n. and a newly discovered relict lineage of Staphylinini (Coleoptera: Staphylinidae). Systematic Entomology 38, 689-707. doi:10.1111/syen.12021

Brunke, A., and Solodovnikov, A. (2014). Male secondary sexual characters resolve taxonomic uncertainty: five new species and a review of the formerly monotypic rove beetle genus Mimosticus Sharp (Coleoptera: Staphylinidae: Staphylininae). Zootaxa 3893, 56-76. doi:10.11646/zootaxa.3893.1.2

Brunke, A. J., Chatzimanolis, S., Schillhammer, H., and Solodovnikov, A. (2016). Early evolution of the hyperdiverse rove beetle tribe Staphylinini (Coleoptera: Staphylinidae: Staphylininae) and a revision of its higher classification. Cladistics 32, 427-451. doi:10.1111/cla.12139

Chani-Posse, M., Brunke, A. J., Chatzimanolis, S., Schillhammer, H., and Solodovnikov, A. (2017). Phylogeny of the hyper-diverse rove beetle subtribe Philonthina with implications for classification of the tribe Staphylinini.

Cladistics, in press. doi:10.1111/cla.12188

Chatzimanolis, S., Cohen, I. M., Schomann, A. S., and Solodovnikov, A. (2010). Molecular phylogeny of the megadiverse rove beetle tribe Staphylinini (Insecta, Coleoptera, Staphylinidae). Zoologica Scripta 39, 436-449. doi:10.1111/j.1463-6409.2010.00438.x

Coiffait, H., and Sáiz, F. (1966). Les Quediini du Chile. Annales de la Société Entomologique de France 2, $385-414$.

De-Silva, D. L., Elias, M., Willmott, K., Mallet, J., and Day, J. J. (2016). Diversification of clearwing butterflies with the rise of the Andes. Journal of Biogeography 43, 44-58. doi:10.1111/jbi.12611

Elias, M., Joron, M., Willmott, K., Silva-Brandão, K. L., Kaiser, V., Arias, C. F., Piñerez, L. G., Uribe, S., Brower, A. V. Z., Freitas, A. V. L., and Jiggins, C. D. (2009). Out of the Andes: patterns of diversification in clearwing butterflies. Molecular Ecology 18, 1716-1729. doi:10.1111/j.1365-294X.2009.04149.x

Goloboff, P. A., and Catalano, S. A. (2016). TNT version 1.5, including a full implementation of phylogenetic morphometrics. Cladistics 32, 221-238. doi:10.1111/cla.12160

Kukalová-Peck, J., and Lawrence, J. F. (1993). Evolution of the hind wing in Coleoptera. The Canadian Entomologist 125, 181-258.

Maddison, W. P., and Maddison, D. R. (2015). Mesquite: a Modular System for Evolutionary Analysis. Version 3.04' Available at http://mesquiteproject.org [03 05 2017].

Miller, M. A., Pfeiffer, W., and Schwartz, T. (2010). Creating the CIPRES Science Gateway for inference of large phylogenetic trees. In 'Proceedings of the Gateway Computing Environments Workshop (GCE),' 14 November 2010 , New Orleans, LA. (xxx.) pp. 1-8. (IEEE: New Orleans, LA, USA.)

Myers, N., Mittermeier, R.A., Mittermeier, C.G., Da Fonseca, G.A. and Kent, J. (2000). Biodiversity hotspots for conservation priorities. Nature 403, 853-858. doi:10.1038/35002501 
Nixon, K. C. (2002). 'WinClada Ver. 1.00. 08.' (Published by the author: Ithaca, NY.) Available at http://www.cladistics.com/wincDownload.htm [xxx].

Parker, J. (2016). Myrmecophily in beetles (Coleoptera): evolutionary patterns and biological mechanisms. Myrmecological News 22, 65-108.

Rambaut, A. (2014). FigTree Ver. 1.3.1. Available at http:// tree.bio.ed.ac.uk/software/figtree/ [03 05 2017].

Rambaut, A., Suchard, M. A., Xie, D., and Drummond, A. J. (2014). Tracer ver. 1.6. Available at http://tree.bio.ed.ac.uk/software/tracer/ [03 05 2017].

Ronquist, F., Teslenko, M., van der Mark, P., Ayres, D. L., Darling, A., Höhna, S., Larget, B., Liu, L., Suchard, M. A., and Huelsenbeck, J. P. (2012). MrBayes 3.2: efficient Bayesian phylogenetic inference and model choice across a large model space. Systematic Biology 61, 539-542. doi:10.1093/sysbio/sys029

Sáiz, F. (1971). Sur les Quediini du Chili (Col. Staphylinidae). Bulletin de la Société d'Histoire Naturelle de Toulouse 106, 364-392.

Seevers, C. H. (1944). A new subfamily of beetles parasitic on mammals, Staphylinidae, Amblyopininae. Field Museum of Natural History 28, 155-172.

Seevers, C. H. (1955). A revision of the tribe Amblyopinini. Staphylinid beetles parasitic on mammals. Fieldiana. Zoology 37, 211-264.

Shorthouse, D. P. (2010). SimpleMappr, an online tool to produce publication-quality point maps. Available at http://www.simplemappr.net [accessed 22 December 2016].

Solodovnikov, A. (2006). Revision and phylogenetic assessment of Afroquedius gen. nov. from South Africa: toward new concepts of the genus Quedius, subtribe Quediina and reclassification of the tribe Staphylinini (Coleoptera: Staphylinidae: Staphylininae). Annals of the Entomological Society of America 99, 1064-1084. doi:10.1603/00138746(2006)99[1064:RAPAOA]2.0.CO;2

Solodovnikov, A. (2012). Rove beetle subtribes Quediina, Amblyopinina and Tanygnathinina: systematic changes affecting Central European fauna (Coleoptera, Staphylinidae, Staphylinini). ZooKeys 162, 25-42. doi:10.3897/zookeys.162.2361

Solodovnikov, A., and Jenkins Shaw, J. (2016). The remarkable Australian rove beetle genus Myotyphlus: its cryptic diversity and significance for exploring mutualism among insects and mammals (Coleoptera: Staphylinidae). Austral Entomology doi:10.1111/aen.12233.

Solodovnikov, A., and Schomann, A. (2009). Revised systematics and biogeography of 'Quediina' of sub-Saharan Africa: new phylogenetic insights into the rove beetle tribe Staphylinini (Coleoptera: Staphylinidae). Systematic Entomology 34, 443-466. doi:10.1111/j.1365-3113.2008.00468.x 
Fig. 1. A 50-\% consensus tree from Bayesian inference analysis. Posterior probabilities over 0.80 are shown at their respective nodes.

Fig. 2. Strict consensus of 96 most parsimonious trees from the maximum parsimony (MP) analysis under equal weights. Circles along branches are unambiguously optimised synapomorphies from WinClada: black circles are unique synapomorphies; white circles are homoplasious synapomorphies. Numbers above the circles are characters and numbers below the circles are states. Values of Bremer support are given at the nodes.

Fig. 3. Habitus of female Devilleferus brunkei.

Fig. 4. Morphological details of Devilleferus brunkei. (A) Scutellum and base of elytra, (B) right protergal gland. Numbers are characters and states from the character matrix.

Fig. 5. Morphological features of Devilleferus brunkei. (A) Hind wing, $(B)$ mesotibia with bifurcate spur, $(C)$ aedeagus in lateral view, $(D)$ aedeagus in parameral view, $(E)$ aedeagus in anti-parameral view.

Fig. 6. Distribution of Devilleferus: paratype of D. brunkei (circle), unavailable specimens of Devilleferus sp. (diamonds).

\section{Table 1. XXX}

Characters are given in italics and character states are given in regular font

(1) Antennae - length of first segment: (0) antennomere I at most as long as antennomeres II and III combined; (1) antennomere I distinctly longer than antennomeres II and III combined.

(2) Antennae - antennomere III, tomentose pubescence: (0) absent; (1) present.

(3) Antennae - antennomere IV, tomentose pubescence: (0) absent; (1) present.

(4) Antennae - apical antennomere: (0) about as long as or, usually, much longer than penultimate; (1) shorter than penultimate.

(5) Head-neck constriction: (0) distinct at sides only; (1) fully developed, distinct all around.

(6) Head - infra-orbital ridge, presence: (0) absent; (1) present.

(7) Head - infra-orbital ridge, anterior extension: (0) not extended more than half the length of gula; (1)

extended more than half the length of gula.

(8) Head - infra-orbital ridge, development of basal portion: (0) present as horizontal ridge between nuchal ridge and postgenal ridge, often minute; (1) turning distinctly dorsally on neck.

(9) Head-nuchal ridge, development: (0) present dorsally and laterally; (1) missing dorsally, present laterally; (2) missing laterally, present dorsally.

(10) Head-postgenal ridge, presence: (0) absent; (1) present.

(11) Head-dorsal basal ridge, presence: (0) absent; (1) present.

(12) Head - ligula, shape: (0) more or less bilobed, with variously developed rounded lobes; (1) compact and entire (or at most slightly notched medially); (2) strongly reduced, indistinct.

(13) Head-mentum, seta $\alpha$ : (0) absent; (1) present.

(14) Head-mentum, seta $\beta$ : (0) absent; (1) present.

(15) Head-mandibles, dorsolateral groove, presence: (0) absent; (1) present.

(10) Head-maxillary palpus, apical segment, shape: (0) more or less fusiform to parallel-sided, sometimes very elongate; (1) aciculate (needle-like and much smaller than previous segment); (2) distinctly expanded towards truncate apex.

(17) Head - maxillary palpus, apical segment, dense, short setae, presence: (0) absent; (1) present. (18) Head-labial palpus, apical segment, shape: (0) more or less fusiform to parallel-sided, sometimes very elongate; (1) aciculate (needle-like and much smaller than previous segment); (2) distinctly expanded towards truncate apex.

(19) Head-labial palpus, apical segment, dense and short setae, presence: (0) absent; (1) present.

(20) Prothorax - hypomeron, superior marginal line: (0) present along entire length of pronotum, not deflexed under anterior angle; (1) present along entire length of pronotum, deflexed under anterior angle; (2) ending at anterior angle (and therefore not deflexed under it). 
(21) Prothorax - hypomeron, inferior marginal line, development: (0) not continued beyond anterior angle of pronotum as a separate entity; (1) continued beyond anterior angle of pronotum as a separate entity.

(22) Prothorax - hypomeron, superior and inferior marginal lines, intersection: (0) lines not intersecting;

(1) lines intersecting.

(23) Prothorax - hypomeron, inflexion: (0) not inflexed (most of its surface visible in lateral view); (1) slightly inflexed (most of its surface hidden in lateral view); (2) strongly inflexed (not visible in lateral view).

(24) Prothorax - front angles: (0) not strongly produced beyond (anteriad of) anterior margin of prosternum; (1) strongly produced beyond (anteriad of) anterior margin of prosternum.

(25) Prothorax - postcoxal process: (0) absent; (1) present.

(26) Prothorax - fusion of pronotum and prosternum: (0) pronotum and prosternum not fused in procoxal cavity, therefore pronotosternal suture complete in cavity; (1) pronotum and prosternum at least partially fused in procoxal cavity, therefore pronotosternal suture missing in part of cavity.

(27) Prothorax - prosternum, longitudinal ridge, presence: (0) absent; (1) present.

(28) Prothorax - prosternum, longitudinal ridge, development: (0) present only on basisternum; (1) present on basisternum and furcasternum.

(29) Prothorax - basisternum, pair of macrosetae: (0) absent; (1) present.

(30) Mesothorax - elytron, sub-basal ridge, presence: (0) absent; (1) present.

(31) Mesothorax - elytron, sub-basal ridge, shape: (0) horizontal, reaching humerus; (1) horizontal but reduced, not reaching humerus; (2) sinuate, directed anteriad.

(32) Mesothorax - elytron, humeral spines or spine-like setae, presence: (0) absent; (1) present.

(33) Mesothorax - mesoscutellum, posterior scutellar ridge, presence: (0) absent; (1) present.

(34) Mesothorax - epipleural row of setae in impressed punctures, presence: (0) absent; (1) present.

(35) Mesothorax - elytron, punctuation: (0) without punctures or setiferous pores; (1) with only a few macrosetae arranged in rows, including epipleuron; (2) with only a few macrosetae arranged in rows, epipleuron with more or less even punctuation; (3) with even punctation on disc and epipleuron.

(36) Procoxa - internal ridge, presence: (0) absent; (1) present.

(37) Procoxa - internal ridge, development: (0) not running along external ridge, ending distinctly before;

(1) not running along external ridge, nearly meeting to entirely fusing with external ridge; (2) running along external ridge.

(38) Metacoxa - transverse carina, presence: (0) absent; (1) present.

(39) Protarsomeres - dorsal chaetotaxy: (0) tarsomeres glabrous, with only marginal setae or at most with a few setae of marginal row duplicated; (1) tarsomeres setose, setae not restricted to marginal series.

(40) Protarsomeres - shape: (0) tarsomeres I-IV more or less cylindrical, not transversely widened and not flattened dorsoventrally; (1) tarsomeres I-IV more or less dorsoventrally flattened and transversely widened.

(41) Metatarsomeres II-V-dorsal chaetotaxy: (0) glabrous along middle; (1) setose.

(42) Metatarsomere IV-ventral spine-like setae: (0) distinctly interrupted medially and removed from apical margin; (1) not distinctly interrupted medially (2-3 setal widths) and not removed from apical margin.

(43) Apical tarsomere - empodial setae, presence: (0) present; (1) absent.

(44) Apical tarsomere - empodial setae, development: (0) one pair of setae; (1) one seta.

(45) Apical protarsomere - empodial setae: (0) distinctly longer than half the length of claws; (1) no more than half the length of claws.

(46) Apical metatarsomere - empodial setae: (0) about as long as that of protarsus; (1) distinctly longer than that of protarsus.

(47) Hind wing, venation, veins CuA and MP4: (0) veins CuA and MP4 completely separate; (1) veins $\mathrm{CuA}$ and MP4 fused in one vein (although its origin from two veins often obvious).

(48) Metanotum - protergal glands, cuticular manifestation, presence: (0) absent; (1) present.

(49) Metanotum - prototergal glands, cuticular manifestation, morphology: (0) shallow impression; (1)

well-developed acetabulum; (2) more or less invaginated capsulae with smaller openings.

(50) Abdominal tergite II - basal longitudinal carina, presence: (0) present; (1) absent.

(51) Abdominal tergite II - basal longitudinal carina, development: (0) entire (connecting anterior margin of tergite with transverse basal carina); (1) extended (extending beyond transverse basal carina); (2) reduced (not reaching transverse basal carina).

(52) Abdominal tergite III - posterior basal transverse carina, presence: (0) absent; (1) present.

(53) Abdominal tergite III - disc, curved ridge, presence: (0) absent; (1) present. 
(54) Abdominal tergite IV - posterior basal transverse carina, presence: (0) absent; (1) present.

(55) Abdominal tergite $I V$-disc, curved ridge, presence: (0) absent; (1) present.

(50) Abdominal tergite $V$-anterior basal transverse carina, development: (0) incomplete; (1) complete, reaching the level of spiracles.

(57) Abdominal tergite $V$-posterior basal transverse carina, presence: (0) absent; (1) present.

(58) Abdominal tergite $V$-disc, curved ridge, presence: (0) absent; (1) present.

(59) Abdominal tergite VI - anterior basal transverse carina, presence: (0) absent; (1) present.

(60) Abdominal sternite III - basal transverse carina, shape: (0) at middle, straight, rounded, or forming an obtuse angle; (1) at middle, sharply pointed and forming an acute angle.

(61) Male-basal mesotarsomere, brush of adhesive setae (not flattened into a broad pad), presence: (0) absent; (1) present.

(62) Male - sternum VIII, apical margin, median emargination, presence: (0) absent, at most vaguely concave; (1) present.

(63) Male - sternum IX, shape of base: (0) more or less symmetrical; (1) weakly to strongly asymmetrical. (64) Male-aedeagus, parameres, separation: (0) paired, well separated; (1) fused into a single lobe (sometimes this lobe more or less secondarily bifurcate).

(65) Male-aedeagus, paramere(s), sensory peg setae, presence: (0) absent; (1) present.

(66) Male-aedeagus, paramere(s), development: (0) paramere(s) not (or at most slightly) produced over apex of median lobe, paramere smaller than median lobe; (1) paramere strongly produced over apex of median lobe, paramere larger than median lobe.

(67) Male-aedeagus, paramere(s), degree of attachment to median lobe: (0) fused to median lobe only at base, paramere(s) distinctly separated from median lobe along entire length; (1) fused to median lobe only at base, very closely appressed to median lobe along entire length; (2) fused to median lobe along entire length, paramere(s) and median lobe hardly (or not) distinguishable from each other.

(68) Female-protarsomeres, adhesive setae, presence: (0) absent; (1) present. 


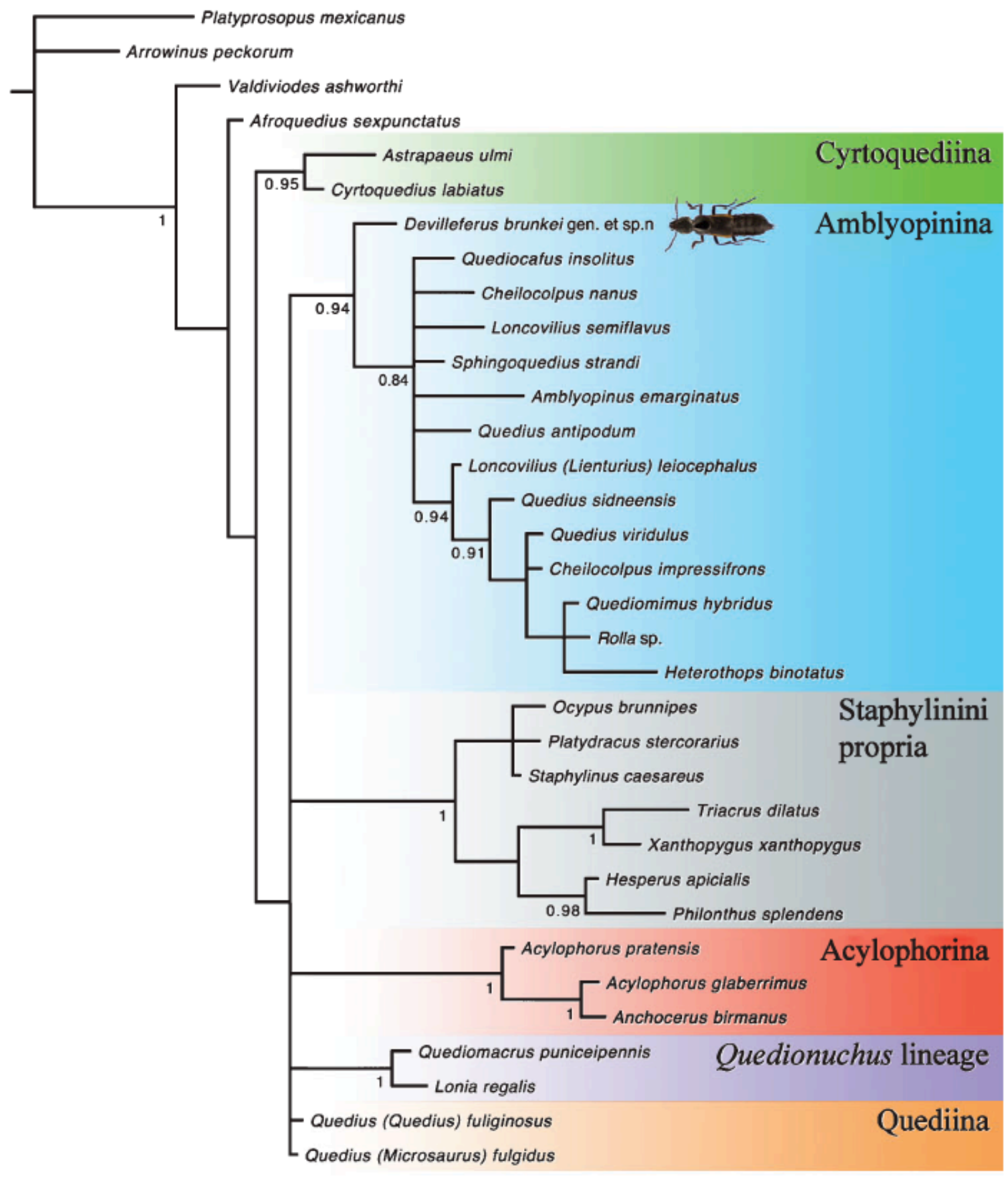

0.08

Fig. 1. A $50-\%$ consensus tree from Bayesian inference analysis. Posterior probabilities over 0.80 are shown at their respective nodes. 


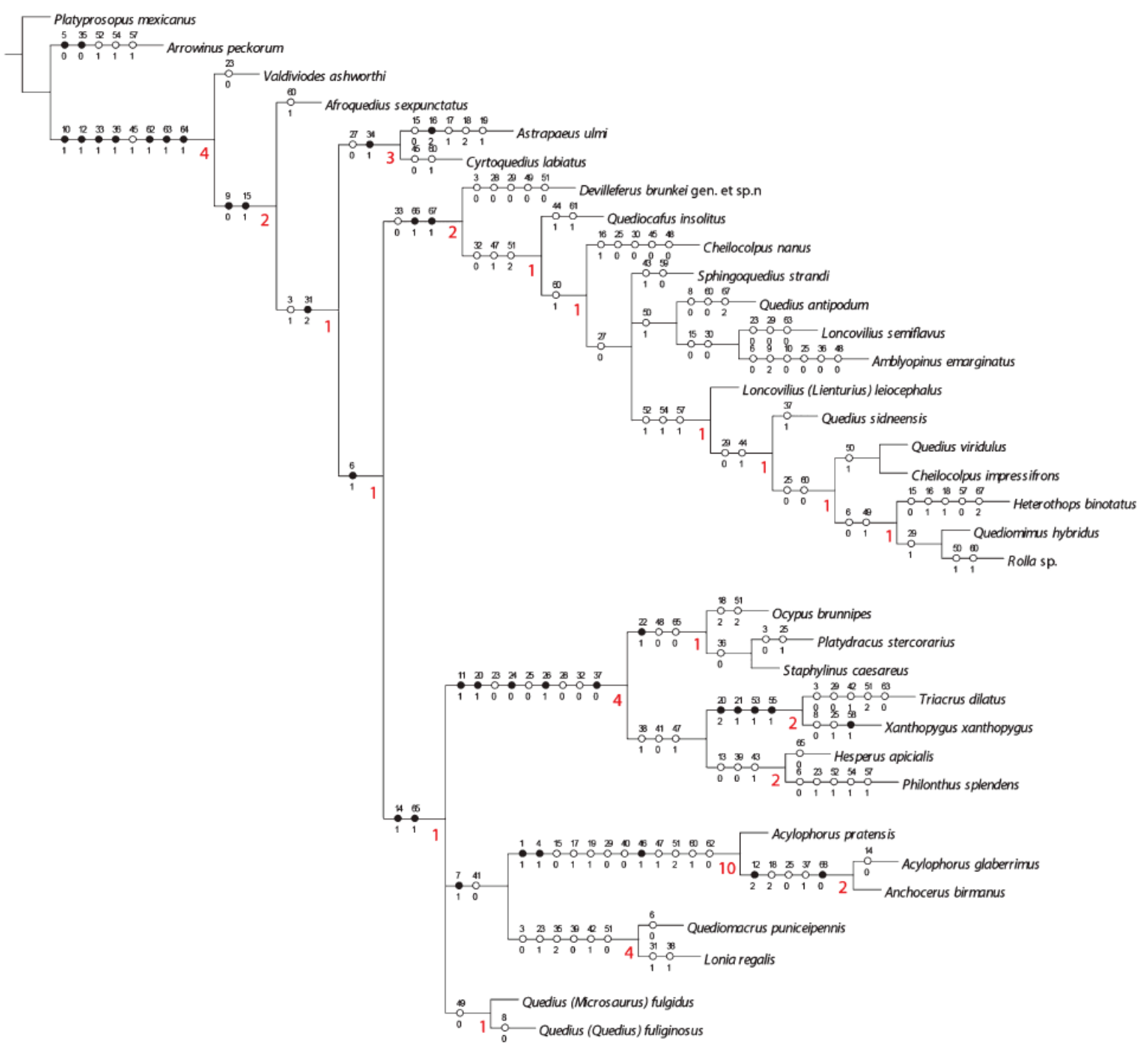

Fig. 2. Strict consensus of 96 most parsimonious trees from the maximum parsimony (MP) analysis under equal weights. Circles along branches are unambiguously optimised synapomorphies from WinClada: black circles are unique synapomorphies; white circles are homoplasious synapomorphies. Numbers above the circles are characters and numbers below the circles are states. Values of Bremer support are given at the nodes. 


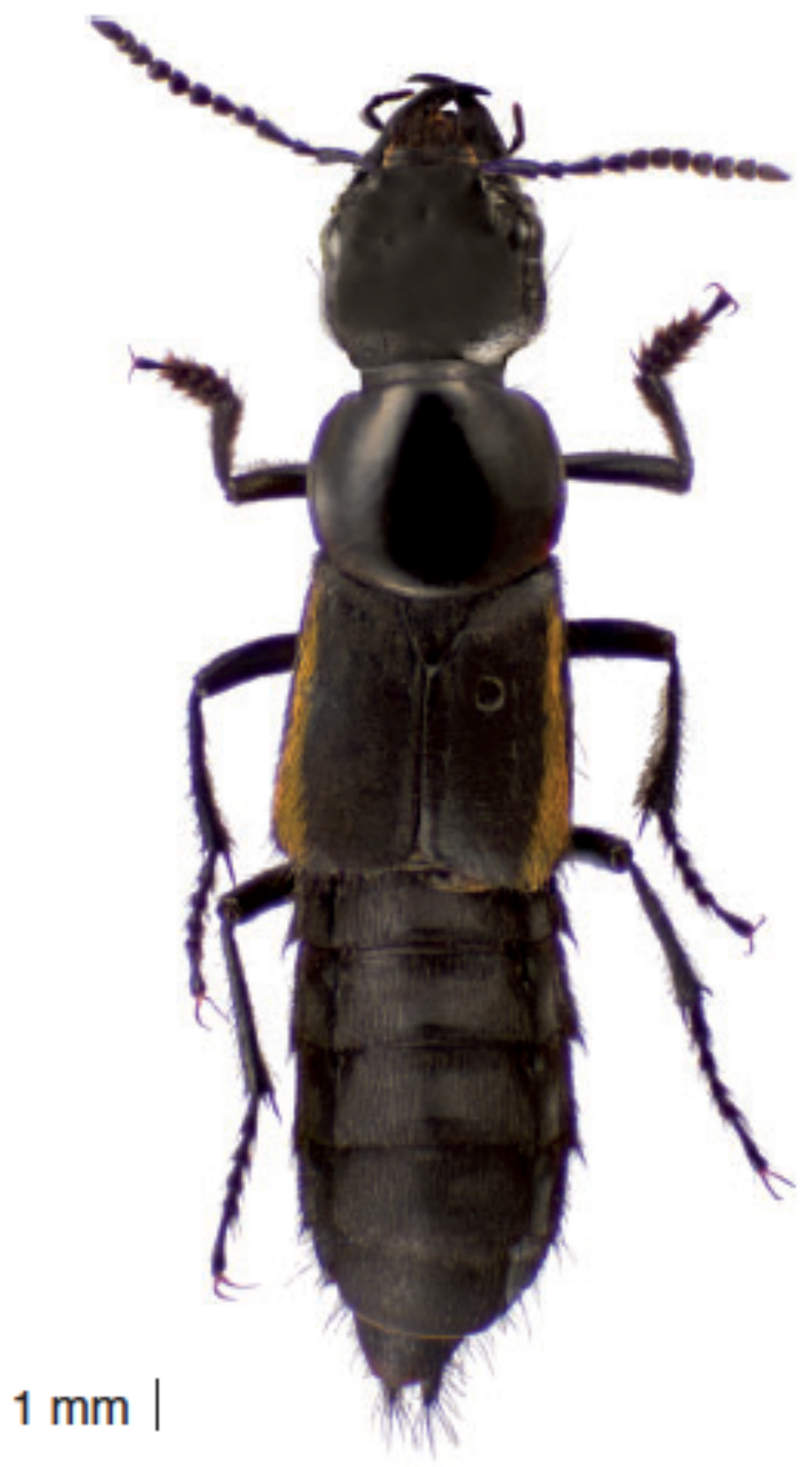

Fig. 3. Habitus of female Devilleferus brunkei. 
(A)
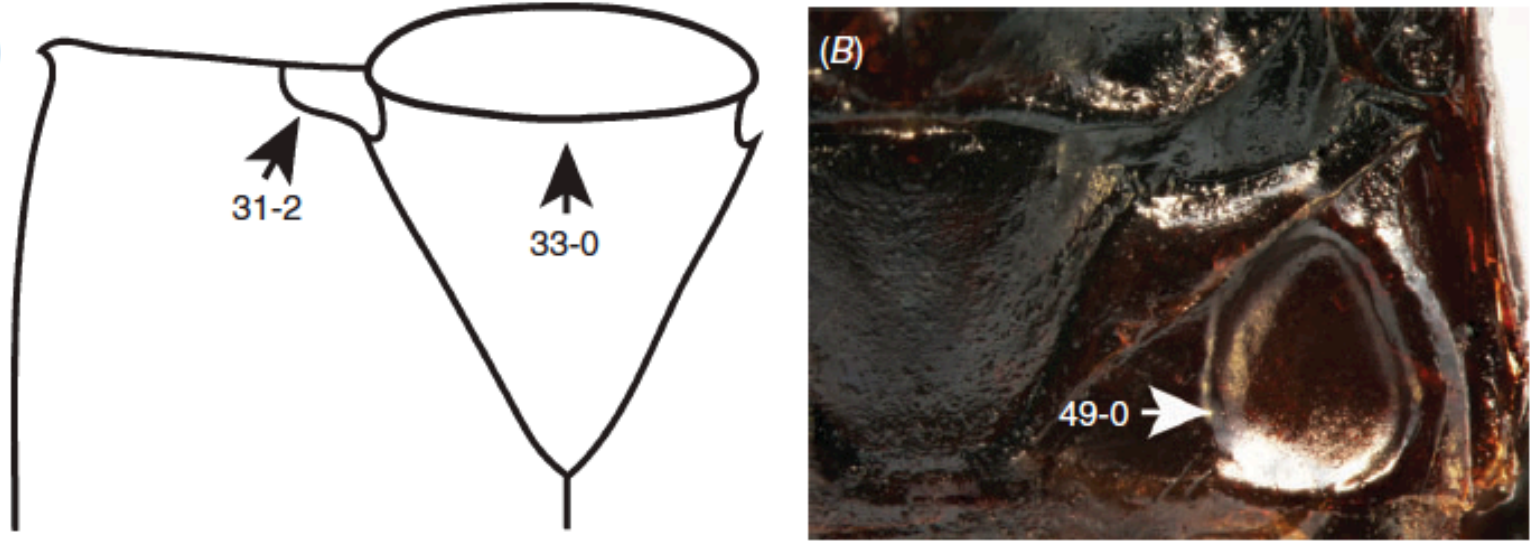

Fig. 4. Morphological details of Devilleferus brunkei. $(A)$ Scutellum and base of elytra, $(B)$ right protergal gland. Numbers are characters and states from the character matrix. 
$(A)$
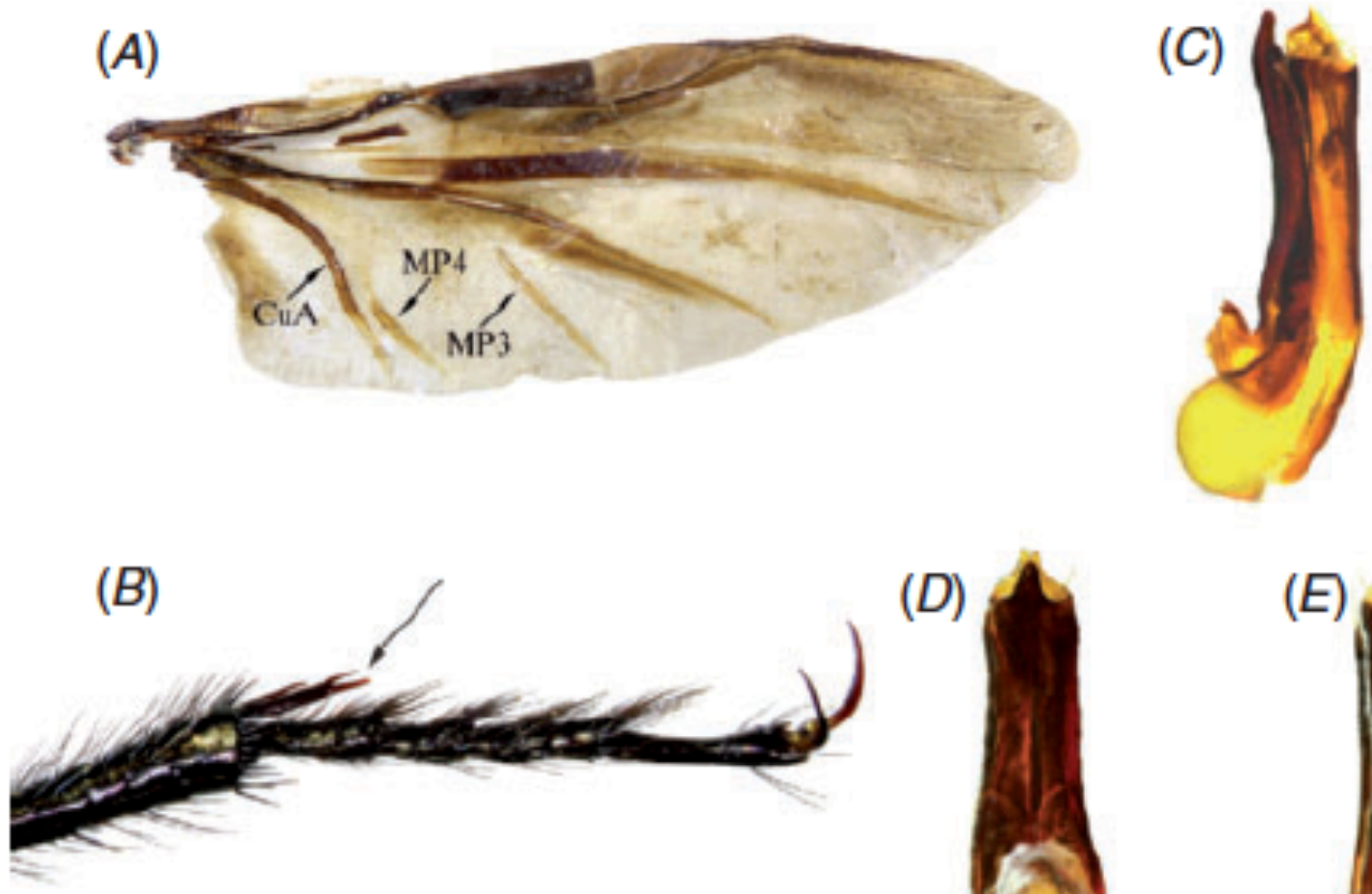

$(D)$

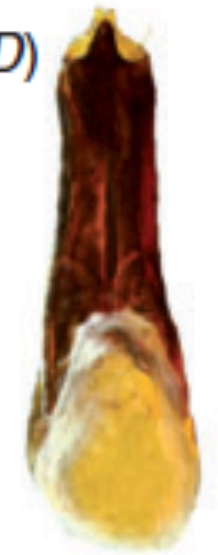

$(E)$

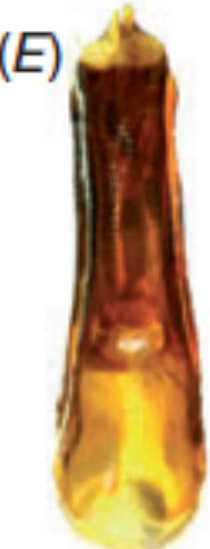

Fig. 5. Morphological features of Devilleferus brunkei. (A) Hind wing, $(B)$ mesotibia with bifurcate spur, $(C)$ aedeagus in lateral view, $(D)$ aedeagus in parameral view, $(E)$ aedeagus in anti-parameral view. 


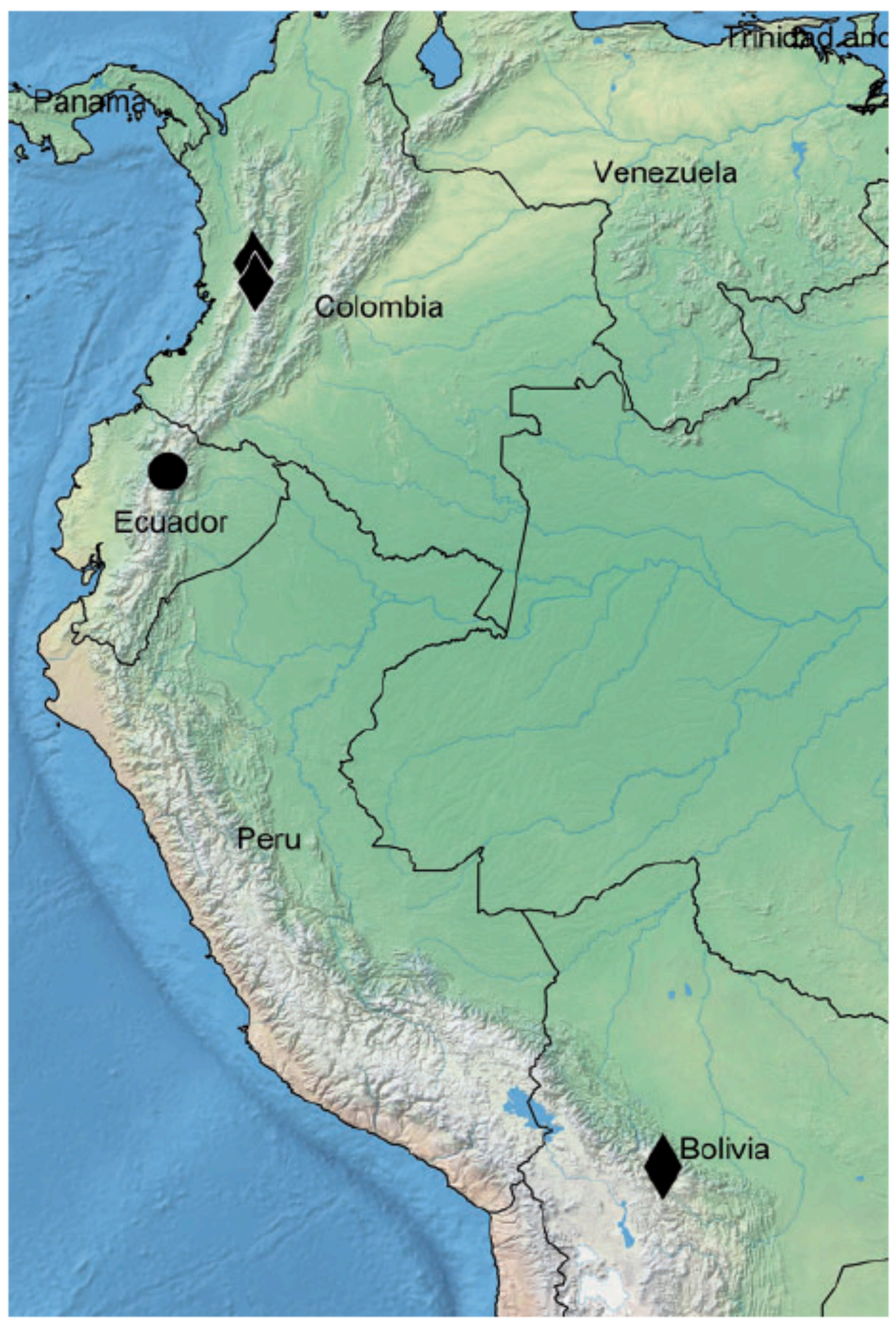

Fig. 6. Distribution of Devilleferus: paratype of D. brunkei (circle), unavailable specimens of Devilleferus sp. (diamonds). 